\title{
LA CENTRALIDAD DEL LENGUAJE EN LA OBRA DE ROGELIO LÓPEZ CUENCA
}

\author{
María FERNÁNDEZ SALGADO \\ Madrid \\ sra.ramsay@gmail.com
}

ogelio López Cuenca (1959) es uno de los artistas españoles que más evidentemente emplea
el recurso de la escritura en su obra; pero ¿qué pasaría si optáramos por relatarlo al revés?
Relatar a Rogelio López Cuenca como uno de los poetas españoles que más imágenes emplea en su trabajo no sería sino un modo de forzar o fabular un dato biográfico bien cierto: que Rogelio López Cuenca fue poeta antes que artista y que como tal, o como una versión contemporánea de tal, podría seguir autoconsiderándose si hiciera falta. Véase si no cómo describe su trayectoria en una entrevista del año 2001:

Mi tránsito de las letras a las artes plásticas no fue una decisión consciente sino más bien una especie de deslizamiento desde un ámbito más conservador, el de la escritura poética, hacia otro no sólo más receptivo a las novedades o a los cruces sino ansioso de ellos... de la planta de anoréxicos a la de bulímicos. De todas formas, me sentía como en un campo de refugiados, con una sensación de provisionalidad que se basaba en la intención de seguir siendo poeta, de considerarme poeta, de la misma manera que Brossa, de decir: el poeta soy yo, la poesía contemporánea es esto. Ahora mismo no me parece ya tan importante: creo que cualquier cosa de interés pasa siempre en las fronteras y que el intrusismo es una de las más saludables actividades y que el florecimiento de «extraños» en los márgenes es lo mejor que le puede pasar a cualquier género (López Cuenca, 2001b)

Sólo un año más joven que Luis García Montero, López Cuenca también estudia Filología Hispánica y comienza publicando a mediados de los ochenta un par de poemarios: Brixton Hill (1986a) y LCR (1986b). Dichos poemarios difieren bastante de cualquier forma poética novosentimental, en la medida en que por ejemplo usan pedazos de fotografías y dibujos, mezclan inglés y castellano, y presentan un tono de aire punk poco comprometido con la exposición de un interior íntimo de autor que delimitaría las posibilidades de la forma poética emergente que el primero representa. Ambos libritos combinan técnicas como el apropiacionismo y el fotomontaje con cierta textura de poema capaz de mantenerse entre los límites de un libro. Que poco después López Cuenca dejara de presentar y pensar su trabajo dentro del circuito poético para hacerlo primero como miembro del colectivo Agustín Parejo School, y después como artista de galerías, revela cierta falta de recepción posible en el seno de lo que quiera que fuese por entonces la poesía nacional. La falta de todo un lenguaje que 
pudiera leer su escritura. La fuga de todo un lenguaje a los dominios no de la poesía. Tal y como he explicado en otro lugar (Fernández Salgado, 2014), lo que el dominio de la poesía española contemporánea pierde históricamente con dicha fuga es, por un lado, toda una colección de textos que, producidos durante el estallido disciplinar que tuvo lugar entre aproximadamente 1964 y 1972, quedan después catalogados dentro de la secundariedad de las etiquetas «experimental», «visual» o «vanguardista»; y, por otro, el camino de acceso que estos textos daban a la intensidad de un lenguaje poético, una memoria de prácticas y un repertorio de procedimientos capaces de producir, tensar, criticar e imaginar las formas de otras lecturas y escrituras posibles. Se pierde la amplitud del rango de variación, innovación e hibridación de los textos que en adelante se escriban dentro del dominio de la poesía y se estrecha el canal del arte hacia buena parte del rico archivo de la poesía contemporánea; mientras se condensa a su vez una suerte de tercer lugar que comprende las fugas del objeto artístico y las fugas del texto literario como formas de habitación, relación y protesta cotidianas: una contracultura que a lo largo de los años ochenta y noventa sustenta las formas de unas prácticas activistas, utópicas y comunitarias como las de la Agustín Parejo School ${ }^{1}$.

La fábula biográfica que aquí interesa no es, entonces, la del poeta adolescente —ni la de la poesía como adolescencia de la creación-, pues son innumerables los ejemplos de artistas que se inician en la creación mediante el protocolo de la poesía. La fábula histórica que aquí interesa es la de unos usos escritos que a la altura de 1986 no caben en la idea mayoritaria de poema y han por eso de fugarse desde el campo literario hacia un campo más abierto a la exploración material de los lenguajes, menos sujeto a nociones liristas del hecho escrito. Antes de partir, en la contratapa de su segundo poemario, López Cuenca deja anotada la renuncia:

Premiado de poeta adolescente [...] renunciará a este mu(n)do y a sus po(m)pas: igual que a servir entra en poeZia, junto con otros más, que lo convencen de que a tan vasto siglo mera literatura no bastara y, así, fundan la Agustín Parejo School, donde meten y sacan las varias artes por el mismo tubo católico de la publicidad y de la guerra que liberan los pobres de la tierra contra de las consignas de los menos mirando por las faltas de los demás (López Cuenca, 1986b).

Rogelio López Cuenca se fuga del destino literario (su mundo mudo y sus pompas popas) para servir a una poeZia cuyas cualidades de cultura «Z» en seguida analizaremos, pero que antes de nada conviene definir como (un) afuera de (un) formato literario (el del libro por ejemplo) y nunca como exterior de una lingüisticidad que sin duda se mantendrá en el corazón de la (in)disciplina practicada por la Agustín Parejo School. López Cuenca se escapa junto a otros ocho fugados de la pintura y la escultura, convencidos todos de que la división general de las artes y (en general) la división social del trabajo, así como el trabajo asalariado mismo y la separación, en fin, de arte y vida, han de llegar a su fin. Convencidos todos de que intentar que tal fin se produzca es la misión que cualquier anartista de bien ha de emprender.

\footnotetext{
${ }^{1}$ Un relato relato historiográfico de esta zona de prácticas puede encontrarse en el reciente Utopías artísticas de la revuelta de Julia Ramírez Blanco (2014).
} 
Aunque este anuncio sea de 1986, la Agustín Parejo School ya venía actuando desde 1981. Su plan para salir de toda objetualidad codificada como Bellas Artes y de toda textualidad codificada como Literatura resulta meridiano. Por un lado consiste en practicar un arte amateur que se confunda con las creaciones de formas de vida que se dan anónimamente en el intercambio cotidiano entre sujetos, siendo paradigmático el sujeto, parece que todavía válido, de «los pobres de la tierra». La Agustín Parejo School plantea interferencias del hacer y el hablar cotidianos. Plantea un arte de obras y no unas obras de arte. Los ejemplos de su obrar son tan dispares como el grupo de «música maquinista proletaria» UHP, la banda de pop Peña Wagneriana, el fanzine Pirata-Pirata o la Coordinadora de Parados Trinidad-Perchel de distribución postal de grabaciones de música, pasando por cerámicas, óleos, camisas estampadas, vídeos, instalaciones y performances. Resulta notable la acción titulada Caucus que realizaron con motivo de las elecciones municipales de 1986. Presentaron a la alcaldía de Fuengirola a un candidato de nombre Moreno, de ideología, digamos, polivalente, mediante una campaña electoral con lemas tan poco comprometidos como «Vota Moreno, vota con garbo» ${ }^{2}$. Esta acción es tan representativa de un arte povera como de un repertorio heurístico propio de jóvenes pobres que hacen del humor y la recreación ociosa formas de vida y de arte. El plan consiste en usar dichos dispositivos para ejercer una suerte de autodefensa comunitaria frente a «las consignas de los menos» que gobiernan y alienan los intercambios ayudados por la pasividad de la masa de «demás» que asiste al expolio embobada. De ahí que APS escoja como canal de la batalla el «tubo» catódico de la televisión y el «tubo católico» de la publicidad, pues es por ambos conductos por donde tales consignas se amasan y condensan materialmente. La Escuela Agustín Parejo opta por emplear una tecnología semiótica ampliada, un «tubo» más parecido al de los medios, capaz de producir textualidades, visualidades y pragmáticas que compitan con la publicidad en soportes similares, conscientes de que el espacio social está extremadamente mediado por los vocabularios verbovisuales que las corporaciones ponen en circulación con el objetivo no sólo de comprar y vender productos, sino de absorber y orientar valores, deseos, costumbres, mitologías y subjetividades. El reto tecnopoético más oportuno del siglo en su opinión consiste en revertir, pervertir o sobreescribir los discursos falsos en los que la economía no sólo semiótica está verdaderamente teniendo lugar ${ }^{3}$. Si la captura que la publicidad realiza de los flujos semióticos colectivos retorna al común como distorsión fetichizada o simulacro; la recaptura, resemantización y recontextualización irónica de dichos torrentes que estos Robin Hood pretenden hacer quiere devolver el poder de significar a las maltraídas y malllamadas masas. Se trata, pues, de un robo, o legítima reexpropiación, para el retorno a la colectividad del valor, uso, trabajo e innovación del que ha sido desposeída.

Es en este sentido de cultura de devolución de la cultura a sus creadores y jugadores anónimos en el que cabe interpretar como justiciera la «Z» de la poética de la Agustín Parejo School. Y es que

\footnotetext{
${ }^{2}$ Para una descripción de todas estas piezas cf. Pujals Gesalí (2003: 152-160).

${ }^{3}$ Comp. con el libro de Marjorie Perloff sobre poesía en los tiempos de los medios audiovisuales, un texto (incluso) anterior al estallido del uso masivo de internet: «Poetry, that is to say, now functions in an arena where the simulacrum (say, the prime time TV melodrama) exerts increasing influence over the way business is actually done in the "real" world» (1991: 198).
} 
además de un término escrito sobre la contratapa de un libro, «POEZIA» también fue una pintada dispuesta sobre los muros de la ciudad de Málaga. A medio camino del grafiti y el agit-prop, se sumó a otras pintadas ejecutadas por la Agustín Parejo School a lo largo de la década aproximada en que operaron: «Namibia libera subito», «Die Kunst is tot! Es lebe die mörderische Kunst der Agustin Parejo School»,

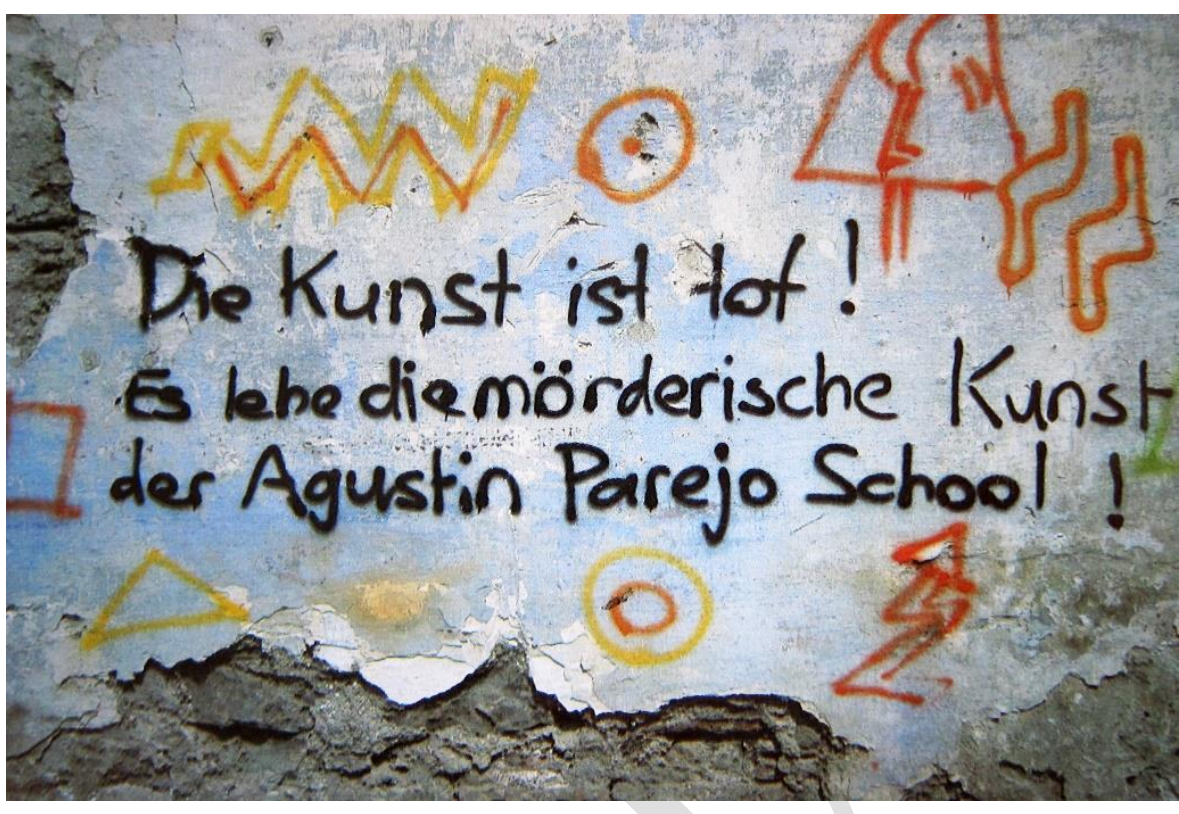

Fig. 1. Agustin Parejo School, Die kunst..., Graffiti, Málaga, 1984. Imagen cortesía del artista. «Málaga Euskadi da». La primera pide en italiano la liberación (o «disponibilidad para el alquiler», según se lea) del país ocupado por la Sudáfrica del apartheid. La segunda versiona el lema en alemán de los dadaístas de la Internacional Dada-Messe George Grosz y John Heartfield que a su vez evoca al constructivista ruso Tatlin [figs. 1 y 2], formando una genealogía del arte nuevo que va de lo maquínico a lo asesino (del arte $)^{4}$. La tercera pronuncia la anexión de la región del sur a Euskadi, recordando a los empresarios fugados del impuesto revolucionario de ETA la causa de sus pesadillas. Las cuatro presentan un pequeño desafío en contenido e idioma, una extrañeza que necesariamente inquietará al viandante; si bien es POEZIA la que por su humorística legibilidad más rara debiera resultar a quien la leyera.

El ceceo de POEZIA remite a un dialecto del andaluz tanto como a un sociolecto popular, a un accidente de corrección del seseo y, por qué no, también a otra pintada de signo extranjerizante: POLIZEI. Cualquiera de estas opciones o todas a la vez vendría a contrastar con el correcto uso altoliterario que cualquier poema normal de la misma época tendría. También y sobre todo vendría a contrastar con la neutralización que de las lenguas locales, bajas, juveniles o meramente lúdicas manufacturan los medios de comunicación a diario. La estandarización de las formas de vida que en torno a las localizaciones territoriales se solían arremolinar, arracimar y transmigrar a través de heteroglosas imposibles de registrar por los satélites de la nueva aterritorialidad global es otra de las homogenizaciones contra las que se levanta la pintada. La tensión lingüística que con tanta guasa y como quien no quiere la cosa POEZIA empieza a apuntar, evidencia en negativo la poca relevancia que la misma le plantea entonces a gran parte de los poetas. Se trata éste de un gesto de geolocalización verbal y que poco tiene que ver con la poesía deslocalizada de la Otra sentimentalidad que por las

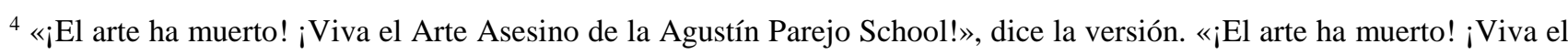
nuevo arte maquínico de Tatlin!» («Die Kunst is tot! Es lebe die neue Maschinenkunst Tatlins»), dice el original de 1920.
} 
mismas fechas se presenta en un manifiesto conjunto de Luis García Montero, Álvaro Salvador y Javier Egea (1983). Como acto de diversión, lúdico y divergente, POEZIA está más emparentada con las raras palabras ácratas que siguen circulando por los entornos contraculturales en boca de, por ejemplo, un cantante de copla como Carlos Cano - que dice «yo creo que el andaluz es la manera árabe de hablar castellano»-, o de la tradición de músicos que desde los Smash cantan con acento y con flamenco ${ }^{5}$. POEZIA es, pues, una versión verbal situada mediante el ajuste ortofonológico, y su diversión del estándar, al habla de su región. Una región que desde el advenimiento de la democracia está llena de instituciones culturales. ¿Cuál podría ser la diferencia real de lo que quiera que sea la «poesía andaluza» respecto a la extremeña o riojana si es que no puede ir, como de hecho jamás va, en $s u$ lengua escrita? Pero por otro lado, ¿existe el andaluz, existe Andalucía? POEZIA es una broma a las nuevas instituciones turístico-culturales autonómicas. Es una provocación a la gran broma que ofrece la neutralidad cultural y aburrimiento vital en la que persisten los lenguajes artísticos regionales y nacionales. POEZIA es, en fin, una mancha en unas paredes donde, según recuerda Esteban Pujals Gesalí, para 1984 no quedaba apenas nada escrito: estaban limpias. Aburridas y obedientes. Retenidas. Detenido el proceso de diálogo público que en ellas tuvo lugar durante el decenio anterior, las paredes de los ochenta registran el avance de un progreso y de un consenso que se van volviendo mudos. «Sois Europeén et tais toi» dice una línea de Rogelio López Cuenca en una lengua comunitaria no española que empieza a confirmar que, en realidad, cualquier plan de nueva minoría escrita respecto de una lengua nacional ha de considerarse dentro de un mapa de isoglosas más que nacionales: europeas, atlánticas, occidentales, mundiales: televisivas. Más que emitidas: recibidas. Cualquier plan de escritura por venir ha de geolocalizar al tiempo que globaliza los verbos en que estamos siendo borrados de la pared.

Manchar la pared. Llenar el hueco. Surificar la cultura del posdesarrollismo: hacer cecear sus imágenes y hacer zozobrar sus consensos. Tal es el leitmotiv de las obras completas de Rogelio López Cuenca, que se caracterizan por suceder afuera los territorios de la cultura nacional y del país de la Literatura, pero no por afuera de la lengua concreta en la que sus habitantes comunican. Y ello a partir de una idea de escritura ampliada y probada por las prácticas anartísticas de los años sesenta y setenta, en la estela de lo que ya habían explorado las vanguardias de finales del siglo XIX y principios del siglo XX.

No hay una distinción material entre la pintada del muro y la palabra del libro. O mejor dicho: sí que la hay pero sólo en lo que se refiere a la discontinuidad material del soporte. La materialidad lingüística de ambas forma una continuidad a la que también adhiere la cualidad manuscrita del grafiti y la cualidad tipográfica del impreso. Ambas son texto, y como tal se diferencian ante el ojo que lo lee

\footnotetext{
${ }^{5}$ Las frases de Carlos Cano pertenecen a una entrevista ya de los años noventa, pero esta actitud era la suya en los años de Transición en los que abanderó un movimiento de recuperación de la copla andaluza: «Hace 500 años que perdí mi lengua» (La Vanguardia, 24/8/1999, p. 64). Smash, la banda germinal de la contracultura peninsular, empezó en 1968 su andadura musical que, según decían en aquel increíble «Manifiesto de lo borde» (1968), no trataba «ni de hacer «flamenco pop» ni «blues aflamencados», sino de corromperse por derecho»y, añadían «sólo puede corromperse uno por el palo de la belleza».
} 
mediante lo que sabe del sentido de las letras, pero también mediante lo que oye en su memoria del oído y mediante lo que ve en su propia memoria óptica. Es decir, que «poeZia» y «POEZIA» están escritas y de este modo es como habríamos de considerarlas. Y leerlas. Pues es la lectura la que propicia la escritura, en un bucle infinito, sin origen. También así, es decir, leyendo, es como podríamos poner en consideración todas las textualidades producidas en los afueras del formato literario, del poema en verso libre o verso medido, del libro mismo. Cualquier operación de contextos, cualquier operación de concepto, cualquier operación de titulado — tan habituales en el campo artístico- enfoca la articulación de la huella significante o archiescritura (Derrida, 1967) que en toda significación se produce — tenga ésta lugar dentro de letras alfabéticas o no-. Y es desde la asunción de esta noción de escritura emitida por el Postestructuralismo de los años sesenta desde donde mejor se leen los objetos producidos antes y después de aquella comprensión del signo. Una comprensión que por un lado permite sortear las estrecheces con las que el alfabetismo (Barthes, 1973) reduce la escritura a la letra impresa en el interior de un libro, y por otro deconstruye la etiqueta de «visualidad» que se aplica a todo aquel fenómeno que a la letra alfabética incomode. No existe la «poesía visual», o sólo existe como epifenómeno de algo de largo más denso, a saber: el descubrimiento de la materialidad lingüística, el espacio abierto y multidireccional de la página, la apertura de la página al exterior del libro, el tiempo no reglado del sonido no medido, la necesidad de un ritmo de aparición en el espacio y en el tiempo que sustituya a la regla perdida, la grafía, la jeroglífica, la letra china, la fonografía, el contexto, la pragmática, y en fin, el mundo material convocado y escenificado a lo largo del archivo de obras de las vanguardias y neovanguardias del XX para todo arte y para toda poesía (y para toda forma de vida) ${ }^{6}$. Esta noción de escritura como articulación significante no sólo atempera la necesidad de las escisiones disciplinares sociohistóricamente sucedidas. Al hacer decaer la errónea escisión entre lo escrito y lo visual, precisamente porque la escritura comprendería la diferencia visual y la diferencia textual como bordes exteriores del significado, reduce la odiosa dicotomía de texto e imagen. Reduce incluso la necesidad de que una imagen haya de aparecer literalmente para que el texto adquiera una cualidad más «visual» que por sí solo, si es que alberga una heterogeneidad verbal suficientemente densa como para diferenciarse materialmente.

En la fértil tradición de la tríada procedimental que conforma la espina dorsal de las vanguardias y neovanguardias del siglo xx, esto es, el collage, el ready-made (o apropiación), y el détournement (o inversión) de materiales tomados, sean éstos imágenes o texto, frases tomadas o frases sumadas a imágenes ya existentes, el trabajo de Rogelio López Cuenca supera la dicotomía imagen/texto por medio de una práctica de escritura muy cercana a la idea recién descrita. La mayoría de piezas de Rogelio López Cuenca disponen las imágenes en tanto léxico con el que operar gramaticalmente y

\footnotetext{
${ }^{6}$ Para un desarrollo más detallado de estas ideas, cf. mi artículo «La poesía visual no es visual» (Hispanic Issues on Line, 2016, en prensa). En este artículo argumento que la poesía comúnmente llamada «visual» no es en absoluto visual, sino que es, como toda poesía, materialmente lingüística. La «visualidad» es una metáfora que apenas funciona para los textos caligramáticos y que no hace sino emborronar nuestra comprensión del cambio formal experimentado por la poesía desde el Un coup de dés de Mallarmé. La poesía mal llamada «visual» es el resultado heteorgéneo y cambiante de la crisis de verso que se abre paso contra la vieja melodía y la antigua noción de semántica del verso medido.
} 


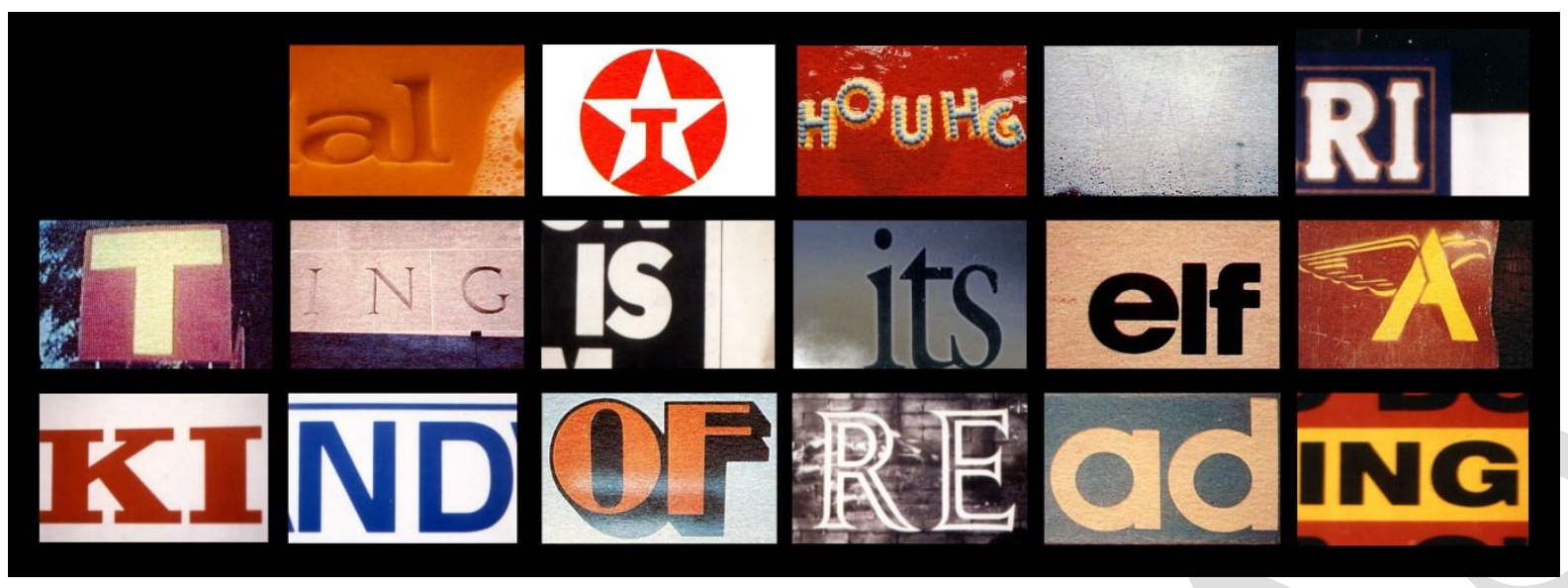

Fig. 2. Rogelio López Cuenca, Read Estate, Instalación, fotografías sobre muro. Dimensiones variables. 1992. Imagen cortesía del artista.

emplean el lenguaje verbal en tanto material tan consistente como aquellas. La articulación de ambas consistencias principalmente resulta mediante la operación de montaje, parataxis o yuxtaposición. Quien efectúa los remontes y desmontes de sentido es quien recibe el texto. La lectura es una forma de escritura y la escritura es una forma de lectura, en tanto en cuanto a ambos lados del collage se ha de hacer por componer igualdades y diferencias; se ha de dotar de continuidad a las discontinuidades, y viceversa. Se ha de hacer, pues, por leer lo escrito en imágenes, o lo escrito en texto, o lo escrito en imágenes y texto. Un fragmento de una de sus piezas de 1993, compuesta a partir de letras extraídas de letreros fotografiados [fig. 2], describe mejor esta poética:

WRITING IS ITSELF A KIND OF READING THE READING OF THE CODENES[?] ARER TO THE COMMUNAL SOURCES OF LINGUISTIC PRODUCTION THAN WRITING SAMEAPP LIES TO ALL OTHER ARTS ALL VERBAL LIKE IT OR NOT

[La escritura es en sí misma un tipo de lectura / La lectura del código más cercana de las fuentes comunales de producción linguiística / Lo mismo puede decirse de todas las demás artes, todas verbales, nos guste o no; la traducción es mía].

Pocos statements más contundentes que el anterior a la hora de reivindicar la centralidad del lenguaje verbal para todas las artes. Pocos argumentos mejores para clasificar la obra de López Cuenca entre las más linguiísticamente conscientes de los últimos tiempos en España. Se podría decir, incluso, que parte del encanto de las obras de Rogelio López Cuenca fundamentalmente radica en la fraseología que despliegan contra, desde y junto a las imágenes con las que se transportan. La capacidad memética, la seductora memorabilidad de sus líneas de texto, procede de algo que podríamos llamar oído fino a todo material verbal exitoso. La frase política: «Detrás de ustedes estamos nosotros», «Los desheredados de la tierra quieren ir a Disneyworld, no a las barricadas» ${ }^{7}$. La frase publicitaria: «Welcome to Paradise». Las agrafías, las cacografías. Este oído hace que cuando Rogelio López

\footnotetext{
${ }^{7} \mathrm{La}$ primera le pertenece al EZLN, es una de tantas frases hermosas y políticamente novedosas enunciadas por el subcomandante Marcos. Fue pronunciada por la mayor Ana María en el discurso inaugural de enero de 1994. La segunda, que presenta también gran atractivo, le pertenece, digamos, al bando contrario: fue enunciada por el periodista Thomas L. Friedman en respuesta a Ignacio Ramonet en una polémica de 1999: «The wretched of the earth want to go to Disneyworld, not to the barricades».
} 
Cuenca, que es también filólogo y lector del Barroco, escribe en forma de poema se traiga prestados metros y paronomasias («Ay veces / por un miedo mayoro las testuces / y me lloro de miedo / esta mi condición misma de bueno / mi condición común de can hallado / y encanallado diluyo mi hueso») (1986b: s/p), y que cuando escribe en forma de títulos se traiga algún verso oportuno de otro poeta («El paraíso es de los extraños», «Une oasis d'horreur dans un desert d'ennui») ${ }^{8}$. Rogelio López Cuenca es capaz de cuadrar el mismo ritmo en dos idiomas ( $\mathrm{I} I$ 'm high on ten gin tonics / y el hígado en salmuera») (1986a: s/p) y escucha tan bien las frases como las morfonologías de las palabras. Así es como elabora juegos verbales que de lejos resuenan duchampianos: «Alien Nation», «No/W/Here», «Andalucinaciones», «Malagana» ${ }^{9}$.

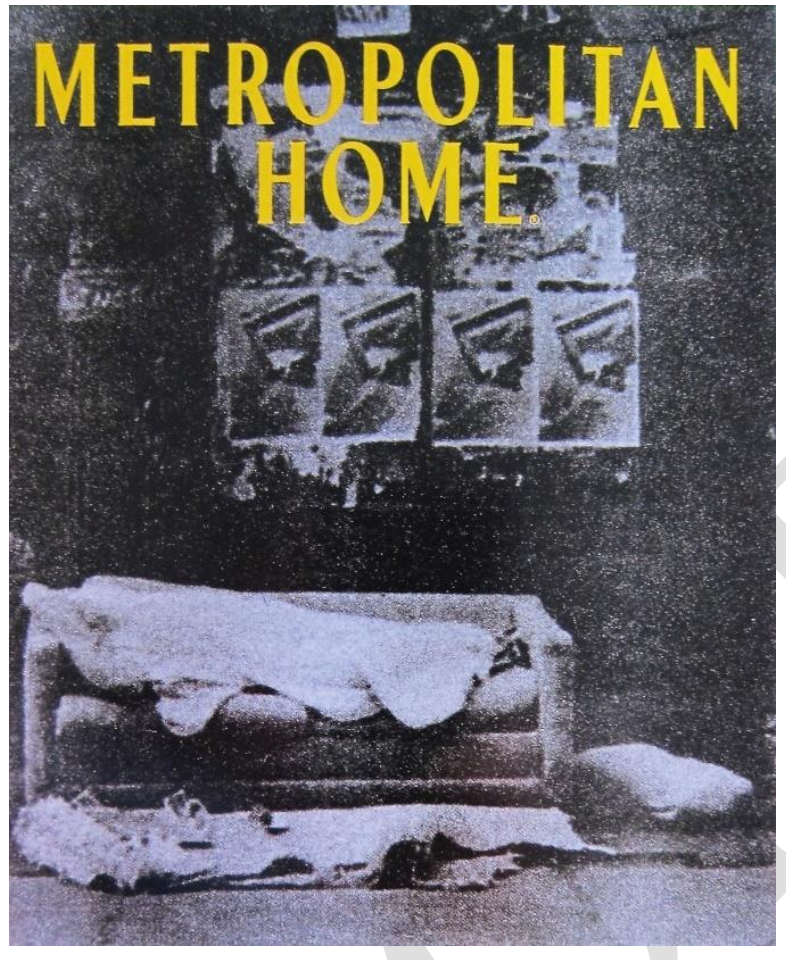

Fig. 3. Rogelio López Cuenca. Metropolitan Home, Pintura sobre fotografía, $98 \times 72 \mathrm{~cm}, 1993$.

Imagen cortesía del artista.

Tomemos como ejemplo de esta noción de escritura de oído fino y de esta práctica escrita expandida el par de trabajos Home Syndrome y Home Swept Hole. Home Syndrome es el título de la exposición en Málaga, en 1993, compuesta por piezas en las que sintagmas y lexemas pertenecientes al campo semántico de «casa» aparecían sobreimpresos sobre imágenes de todo tipo de «hogares» — desde el sofá callejero de un homeless que hace de portada de una revista de la revista Metropolitan Home [fig. 3], a La chambre de Van Gogh, pasando por un campo de refugiados- Home swept hole es el título de una publicación de iguales coordenadas por Ediciones Originales. Por cierto que este texto, que incluye las letras de anuncios por palabras y excluye las fotografías, ha sido reeditado en 2013 [figs. 4 y 5]. Una versión de esta obra formó parte del trabajo expuesto por Rogelio López Cuenca en la Bienal de São Paolo del año 2002, de cuya publicación, titulada Astilhãografo (2002), es de donde procede el texto que yo manejo y cito.

${ }^{8}$ El primero es de Amin Maalouf y da nombre, por un lado, a un proyecto en curso desde 1999, y por otro a una muestra de 2001 de la que existe un libro editado (2003). El segundo es un verso muy conocido de Les fleurs du mal (1857) de Charles Baudelaire, que aparece sobreimpreso sobre un sol componiendo un no muy típico cartel de publicidad turística (recogido en López Cuenca, 2002).

${ }^{9}$ Alien Nation es el nombre de una exposición de Rogelio López Cuenca en la galería Juana de Aizpuru de Sevilla, en 1992. No/w/here, que juega con «En ningún lugar», «Aquí no» y «Ahora aquí», es un cartel de 60 x $48 \mathrm{~cm}$. que presenta la fotografía de unos refugiados republicanos españoles cruzando la frontera en 1939, y fue mostrado varias veces (cf. López Cuenca, 2000: 82-83). No/w/here también nombra después una compilación o collage de trabajos de Rogelio López Cuenca al hilo de la migración, el exilio y el viaje, expuesta y editada con forma de postales por Tecla Sala (L'Hospitalet de Llobregat, 1997/1998). Andalucinaciones es el nombre de una muestra en el Teatro Central de Sevilla y la Biblioteca de Andalucía de Granada en 1997. Y Malagana es el nombre de un proyecto de distribución por mail y por postales de diferentes imágenes históricas de Málaga, que tuvo lugar entre 1999 y 2000; cf. la web: www.malagana.com (última consulta, 10/1/2016). 
Home swept hole es un listado de palabras en varios idiomas, del latín al alemán, que pertenecen al campo semántico de casa u hogar y a las topologías ampliadas del lugar de habitación; por ejemplo: «Ningures», «Soberanía», «Virtual Space», «Hortus Conclusus». Las palabras están tomadas de revistas y extraídas fundamentalmente de anuncios de venta, alquiler y hostelería («chaves na mão», «Sin entrada», «luxo”), aunque la serie ofrece ocasiones de variación sospechosamente provocada: «Acosados», «chabola todo exterior / choza con puerta blindada». A lo largo de la obra se suceden los versos bien reconocibles («corrientes aguas puras, cristalinas», «iVivir en los pronombres!»), los intertextos («Naked City», «Machine-à-Habiter») y los encuentros menos que fortuitos, divertidos («Pocilga / Porcelanosa»), políticamente incorrectos («Zulo», «GAZA STRIP», «TERRITORIOS OCUPADOS») e inesperados («Jaima mármol y parquet»). Cada tanto a lo largo de la serie, entre dos
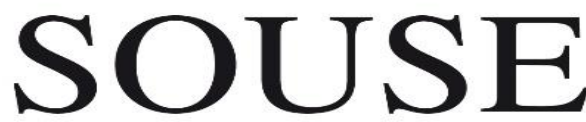

SWING
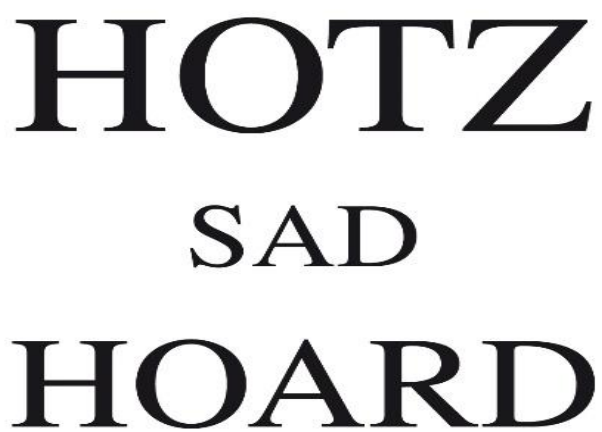

SWIRL

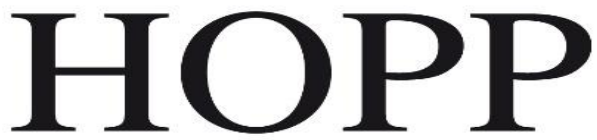

$\mathrm{TPLX} * \mathrm{GRDN} * \mathrm{FPLC}$

$\mathrm{A} / \mathrm{C} *$ Laund $\mathrm{Rm}$

Ningures

Villa Madama

Hospedagem Ilegal

Fontanería secreta

Autonomía total

Stanza in basement finito

GEHEIM KERKER

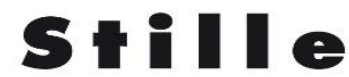

O ubli ette

I mpunidad

Watergate

Top security

Call owner

Figs. 4 y 5. Rogelio López Cuenca. Home Swept Hole, Libro [pp. 23-24], 1992. Imagen cortesía del artista.

y tres palabras organizan un sonido parecido al del famoso adagio Home Sweet Home (Hogar Dulce Hogar) si bien juegan a enrarecer el sentido de seguridad de tal afirmación: «síndrome de hogar», «hogar barrido agujero». Se trata de empastes de sílabas sobre los que se superponen los acentos de la frase primera sin importar tanto la corrección fonética de los idiomas a los que pertenecen: «HAUS Sweat HÖLLE sioux HOST swiss HOWL», «DOUSE swim HOLD Swab Hoax Swine Honk», «HOSE sume HOTS suite HORT zip ROW», «HOUND sea FOAM suff HORS Txit HUTCH», «SOUSE 
swing HOTZ Sad HOARD swirl HOPP», «Digs Cell dump», «CAU Schwimmbad», «HORDE sumpf HORN suede CLONE», «HOARSE swill HONTE tit ROAN Stock HOLM», «HÖCHST Strip HOHN twin HELL swamp HÔTE», «DOSE Sex HOOD swap OURS switch HOD», «LOUSE sic HOHL sleet HATE süb HOOK», «HAUSSE sühn LOAM Shit HOCH seams GROAN», «GROUSE seize ROAM swash Haß sick HOPE».

Gracias a la estabilidad del campo semántico de «casa», las haches que van hilando los adagios, el acento que se sobrepone a tales palabras y, en fin, la recurrencia de aparición de formas gráficas y acústicas análogas, se vuelve posible leer con facilidad los varios idiomas del texto. El saber que casi en cada línea aparecerá una casa propicia el panlingüismo, en una suerte de ejercicio lexicográfico invertido, por el cual primero conocemos la acepción y después es cuando escudriñamos el término. Este ejercicio de predicción y relleno no es muy diferente del que constantemente hacemos en nuestra lengua nativa a la hora de comunicarnos, pero queda enfatizado por su necesidad.

La multilingüisticidad es un signo tan propio del mercado internacional del arte en que se mueve López Cuenca como de la publicidad que cada día nos convence de comprar productos más confiables si vienen en otro idioma, preferentemente inglés. El hecho de que la casa pueda ser concebida como objeto de consumo — del mismo modo que lo es el amor romántico de las «escapadas», la belleza de «los cosméticos» o la «aventura» de los «tours»— se ve muy bien enfocado a la luz de la apropiación de tamaños y tipografías de las letras de revista. Las formas tipográficas por sí mismas conforman un catálogo de casas que no necesita mostrarnos fotografías para enseñarnos las cualidades y calidades de las mismas, precisamente por la cualidad escrita a la que antes aludíamos. Una escritura que propicia una imaginación que es producida por letras, grafías y sonidos tanto como lo sería si estuviera producida por imágenes, siendo la diferente gradación de las presencias un asunto menos dependiente de la cantidad visual que de la articulación material de los significantes — tal y como se observa al comparar la figura con fotografía de Home Syndrome [fig. 3] y la figura sin fotografía de Home Swept Hole [figs. 4-5]. El resultado es un texto cuya calidad sonora conforma texturas tipográficas que conforman ritmos gráficos que refuerzan ritmos silábicos, y hasta rimas («Undersized / Overpriced»), que informan una serie muy buena de frases que apenas han sido emanadas por autor alguno, o mejor, por un único autor. El autor es un selector y montador muy virtuoso en el uso del metrónomo de acentos, líneas, espacios y grafías.

Home swept hole formó parte de Astilhãografo, una instalación producida para la Bienal de São Paulo de 2002. Este trabajo mostraba una suma condensada de los tópicos, piezas de imaginario y lenguas que componen la obra de López Cuenca (López Cuenca-Chillida, 2002). Mientras Home swept hole demarcaba los límites de un espacio típicamente privado como el de la casa, la otra parte de Astilhãografo se constituía como un «poema circulatorio» que presentaba el otro espacio urbano por definición: el espacio público. El hilo de montaje de Astilhãografo es la representación gráfica de una línea de metro alrededor de la cual se distribuyen algunas reproducciones de obras anteriores de Rogelio López Cuenca y de una gran cantidad de textos apropiados, en los dos sentidos, para la ocasión. Las falsas portadas de un Vogue soviético, Word\$ Word\$ Word\$, «Une oasis d'horreur...»o 
Bienvenidos son algunas de las piezas convocadas para la ocasión ${ }^{10}$. El viaje de lectura que el poema dispone entre ellas conduce por una topología de la globalización capitalista desde sus orígenes en el comercio Mediterráneo: de la esclavitud del trabajo proletario, a la migración que inicia el grueso de los viajes alrededor de la tierra; de las lenguas que circulan, al paradigma del dinero; de la fluidez del dinero, a la estrechez, real y fonética, del Estrecho y de Schengen, por paronomasia; y en fin, de la condena de las poblaciones de la tierra, a la movilización total de su existencia en función de unas consignas que no les pertenecen. La novedad aquí radica en el hilado paratáctico de las tres zonas topológicas - trabajo, lengua, circulación - para la formulación de un concepto de lenguaje que las engloba. El lenguaje es definido como un trabajo, trabajo de lenguaje, que genera, por lo tanto, capital lingüístico, y también, por lo tanto, alienación. Esta alienación define por un lado al «obrero lingüístico» que «no sabe lo que hace ni por qué», y por el otro, al flujo impersonal de dinero verbal que produce la invisibilización de tal estado de despojamiento. Hay, pues, un «hablar dinero» que «es editar monedas acuñar / como se acuña un término decir / tan sólo definido por el uso: / tener hambre o frío / tener hambre o sed», es decir, carecer de los verbos que no se emplean por no ser concebidos en el uso necesitado. Y hay, en contra, un uso creativo, popular o literario, que interviene acuñaciones, deshace frases hechas e interrumpe el librecambio del entendimiento abriendo, como lo hacía Zaum, un «No under standing time»: un tiempo diferente o extraño, pero que no va por debajo, sino que está de pie. Una otra comunicación, liberada de la necesidad. Emancipada.

«Word is a four letter work» dice el verso que acaso mejor formule estos apuntes sobre economía lingüística. La frase manipula un clásico leitmotiv de la cultura punk y el título de una canción de los Smiths (que a su vez es una versión de Cilla Black), que dicen «Work is a four letter word». El giro fraseológico por un lado afirma que la palabra, cualquier palabra, es un trabajo plástico, material, y es, por ello, un trabajo económico de signo proletario. El giro por otro lado confirma el espíritu de repulsión contra el trabajo que traía la frase original, pues cuatro letras son tan necesarias para hacer la palabra «word», como también es cuatro el molde de cantidad de las palabras más vulgares y ofensivas del inglés: «fuck», «slut», «shit», «damn», «hell», etc. La idea que resulta es bien compleja, pues si un número de letras es necesario para escribir con orgullo cualquier palabra, cuatro hacen falta para que resulte evidente la condena a la que está sometida la lengua del trabajador. Desde la perspectiva de este marxismo rossilandiano (Rossi Landi, 1968) toda emancipación primero pasa por hacer consciente la alienación. Bajo esta descripción de la lucha de clases, digamos, poética, puede leerse Astilhãografo como un repertorio de los pedazos de la historia del siglo de los oprimidos de la lengua, de los excluidos del corpus central de la Lírica Nacional que los infrarepresenta; una suerte de tesoro lo- $f i$ a partir del que se puede reconfigurar el valor y el uso de la lengua de cualquiera: vanguardias rusas, himnos, eslóganes, frases hechas, canciones, lenguaje coloquial, refranes, Marx, Pound, Duchamp, Mallarmé, Debord, Rimbaud, Baudelaire, Maiakovski, Cendrars, Marinetti, De

\footnotetext{
${ }^{10}$ Del proyecto Word\$ Word\$ Word\$ hay libro (López Cuenca, 1994). De las portadas a lo soviético del Vogue puede encontrarse noticia en el prólogo a Obras escrito por Juan Antonio Ramírez (2000: 11-30) y en el texto de Esteban Pujals Gesalí para Bienvenidos (2001a), entre otros. Sobre Bienvenidos cf. también mi artículo de 2010.
} 
Certau, Virilio, Augé, Wittgenstein, Pessoa, Cavafis, Hölderlin, poesía popular de canciones propias de comunidades inmigrantes, palabras en tupí, en portugués, en francés, ruso, árabe, alemán, etc.

El anterior es un archivo que podría ser compartido por aquellos poetas y artistas dispuestos a fugarse de las falsas escisiones de la materialidad lingüística y de la tradición cultural escindida que todavía las sanciona. Mientras esperamos a la reconexión, el archivo anterior enriquece nuestra lectura de la obra de artistas como Rogelio López Cuenca. La misma lectura enriquecida nos haría afirmar ante la ficticia pregunta con la que comenzaba este artículo que de ningún modo él es poeta por haber escrito poemas alguna vez. El uso intensivo del lenguaje, la idea de escritura expandida con la que opera y el oído fino de las lenguas, son los que harían de él un poeta si hiciera la menor falta.

\section{Bibliografía}

BARTHES, R. (1973): «Variaciones sobre la escritura», en Variaciones sobre la escritura. Trad. Enrique Folch González. Barcelona, Paidós, 2002.

- (1982): Lo obvio y lo obtuso. Trad. C. Fernández Medrano. Barcelona -Buenos Aires - México, Paidós, 1986.

DERRIDA, J. (1967): De la gramatología. Trad. Óscar del Barco y Conrado Ceretti. Madrid, Siglo XXI, 1978.

FERNÁNDEZ SALGADO, M. (2010): «Bienvenidos (a la Europa fortaleza). El nomadismo verbovisual de Rogelio López Cuenca contra las fronteras», en Diana LóPEZ MARTínEZ, ed., Actas del XI Congreso Internacional de Literatura española Contemporánea. Santiago de Compostela, Andavira.

(2014): El Momento Analírico. Poéticas constructivistas en España desde 1964 (tesis doctoral).

Madrid, Universidad Autónoma de Madrid; en https://repositorio.uam.es/handle/10486/664043 (última consulta, 22-6-2016).

García Montero, L. - SAlvador, Á. - EgEA, J. (1983): «La otra sentimentalidad», en F. J. DíAz dE CASTRO, ed., La otra sentimentalidad. Estudio y antología. Barcelona, Fundación José Manuel Lara, 2003, pp. 37-40.

LóPez CuENCA, R. (1986a): Brixton Hill. Málaga, Newman.

(1986b) LCR. Málaga, Centro cultural de la Generación del 27 - Diputación de Málaga.

(1992): «No surprise for the gander», en Ein Graeme Murray, ed., Poiesis. Aspects of contemporary poetic activity. Edinburg, The Fruit Market Gallery, pp. 96-97.

(1993a) Rogelio López Cuenca. Málaga, Unicaja.

(1993b): Home swept hole. Barcelona, Ediciones Originales [2 edición, 2013].

(1993c): Catálogo de la exposición de la «3a Beca Picasso para las artes plásticas». Málaga,

Fundación Pablo Picasso - Museo Casa Natal - Ayuntamiento de Málaga.

(1994): Word\$ Word\$ Word\$. Barcelona, Junta de Andalucía.

(2000): Obras. Granada, Diputación de Granada. 
112 Tropelías. Revista de Teoría de la Literatura y Literatura Comparada, 26 (2016)

María Fernández Salgado

(2001a): Bienvenidos. Granada, Centro Andaluz de Arte Contemporáneo.

(2001b): «Lo más interesante pasa siempre en la frontera», entrevista en El Cultural (2-5-2001), en http://www.elcultural.es/version_papel/ARTE/850/Rogelio_Lopez_Cuenca (última consulta, 10/1/2016).

- (2003): El paraíso es de los extraños. Málaga, CEDMA. (2009): Hojas de ruta. Granada, Museo Patio Herreriano.

LóPez CuencA, R. - ChILlidA, A. (2002): Astilhãografo. Catálogo de exposición en la XXV Edición de la Bienal de Sao Paulo, Iconografías metropolitanas. Pabellón de España, 23 de marzo a 2 de junio de 2002. Madrid, MAE - Secretaría General para la Cooperación Internacional e Iberoamericana - Dirección General de Relaciones Culturales y Científicas.

Perloff, M. (1991): Radical Artifice. Writing poetry in the age of media. Chicago, University of Chicago Press.

Pujals Gesalí, E. (1989): «Agustín Parejo School: Po-ética de la renuncia», Arena Internacional del Arte, 3, pp. 60-64.

(2003): «El arte de la fuga: modos de producción artística colectiva en España 1980-2000», en

J. CARrillo e I. Estella, eds., Desacuerdos. Sobre arte, políticas y espacio público en el Estado Español. Barcelona, Arteleku - Diputación de Granada - MACBA - UNIA, vol. I, pp. 152-160.

RAmírez Blanco, J. (2014): Utopías artísticas de la revuelta. Claremont Road, Reclaim the streets, la Ciudad de Sol. Madrid, Cátedra.

Rossi LANDI, F. (1968): El lenguaje como trabajo y como mercado. Trad. Italo Manzi, Caracas, Monte Ávila, 1970. 